\title{
A ENTIDADE FAMILIAR CONTEMPORÂNEA E O AFETO COMO GERADOR DE VÍNCULO DE PARENTALIDADE: A SOLIDIFICAÇÃO DA MULTIPARENTALIDADE POR MEIO DO REGISTRO CIVIL
}

\author{
Francielle Benini Agne Tybusch" \\ Luan Martins Lemos**
}

RESUMO: A entidade familiar brasileira, ao longo do tempo, passou por diversas transformações. Partindo-se de uma concepção clássica e conservadora, podese afirmar que atualmente é mais flexível e voltada para a felicidade de seus componentes. Nesse sentido, considerando a tendência de se possibilitar o reconhecimento da multiparentalidade, viabilizando-se que o filho faça constar no seu registro o nome de dois pais ou duas mães, por exemplo, questiona-se, como será realizado o seu registro na Serventia de Registro Civil das Pessoas Naturais? O método de procedimento utilizado foi o monográfico e a técnica de pesquisa foi a bibliográfica e documental. Ao fazer uma análise do estudo, pode-se constatar que a legislação pátria ainda é omissa nesse assunto. Mesmo diante dessas omissões, os tribunais não estão deixando os demandantes desamparados. Com vista à preservação da dignidade da pessoa humana e à proteção do melhor interesse da criança e do adolescente, surge, a multiparentalidade.

PALAVRAS-CHAVE: Multiparentalidade; Afetividade; Registro civil.

\section{THE CONTEMPORARY FAMILY AND AFFECTION AS THE GENERATOR OF PARENTAL LINK: THE SOLIDIFICATION OF MULTI-PARENTS STANCE THROUGH CIVIL REGISTRATION}

ABSTRACT: The Brazilian family has experienced different transformations throughout time. Compared to the classical and conservation conception of the family, one may state that today it is more flexible and aims at the happiness of its members. The trend to acknowledge the multi-parents conditions and making possible that offspring put on their birth certificate the name of two father or two mothers, demands how registration of the name in the Civil Registry may occur. Research is bibliographical and documental in current monograph. Analysis on the matter shows that Brazilian law is faulty and lacking, even though the Courts are

\footnotetext{
"Doutora em Direito pela Universidade do Vale do Rio dos Sinos (UNISINOS). Docente do Curso de Direito da Universidade Franciscana (UFN). Docente Substituta do Departamento de Direito da Universidade Federal de Santa Maria (UFSM), Brasil. E-mail: francielleagne@gmail.com

** Especializando em Direito Público: Constitucional, Administrativo e Tributário pela Estácio. Bacharel em Direito pela Universidade Regional Integrada do Alto Uruguai e das Missões (URI/Santiago).
} 
taking their own decisions. Multi-parents condition occurs for the preservation of the dignity of the human person and the protection of the child's best interests.

KEY WORDS: Multi-parents condition; Affection; Civil registration.

\section{LA ENTIDAD FAMILIAR CONTEMPORÁNEA Y EL AFECTO COMO GENERADOR DE VÍNCULO DE VIDA PARENTAL: LA SOLIDIFICACIÓN DE MÚLTIPLE PARENTAL POR INTERMEDIO DEL REGISTRO CIVIL}

RESUMEN: La entidad familiar brasileña, a lo largo del tiempo, pasó por diversas transformaciones. Partiéndose de una concepción clásica y conservadora, se puede afirmar que actualmente está más flexible y volcada a la felicidad de sus componentes. En ese sentido, considerando la tendencia de posibilitarse el reconocimiento de la múltiple parental, posibilitándose que el hijo haga constar en su registro el nombre de dos padres o dos madres, por ejemplo, se cuestiona, ecómo será realizado su registro en la Oficina de Registro Civil de las Personas Naturales? El método de procedimiento utilizado fue el monográfico y la técnica de investigación fue la bibliográfica y documental. Al hacer un análisis del estudio, se pudo constatar que la legislación patria aún es omisa en ese tema. Aun delante de esas omisiones, los tribunales no están dejando los demandantes desamparados. Con vista a la preservación de la dignidad de la persona humana y a la protección del mejor interés del niño y del adolescente, surge, la múltiple parental.

PALABRAS CLAVE: Múltiple parental; Afectividad; Registro civil.

\section{INTRODUÇÃO}

Com o decorrer dos anos, constatou-se que a entidade familiar passou por diversas modificações. No Brasil, somente após a promulgação da Constituição Federal de 1988 foram definitivamente rompidos os traços discriminatórios característicos do Código Civil de 1916. Com vista à preservação da dignidade da pessoa humana e inspirada em valores morais contemporâneos, a Constituição Federal aumentou o espectro da família, reconhecendo outras formas de composição da entidade familiar, além do matrimonial.

Atualmente há o entendimento de que o alicerce da família contemporânea se encontra fundado na afetividade. Além disso, o Supremo Tribunal Federal acabou 
por valorizar a filiação socioafetiva, elevando-a ao mesmo patamar que o havido pela biológica. Nesse sentido, a multiparentalidade busca possibilitar a cumulação dos vínculos, biológico e socioafetivo, com o seu devido registro legal, visando efetivar as diversas relações havidas de fato, assim como é na realidade.

Pois bem, dessa maneira objetiva-se analisar brevemente a evolução histórica das entidades familiares no Brasil, fazendo uma alusão aos fatores que contribuíram para a sua atual projeção no ordenamento jurídico. Do mesmo modo, estuda-se de que maneira a afetividade passou a ter importante papel jurídico, tendo em vista que, atualmente, é vista como o fator mais importante para a solidificação de uma entidade familiar.

Nesse sentido, considerando a tendência de se possibilitar o reconhecimento da multiparentalidade, viabilizando-se que o filho faça constar no seu registro o nome de dois pais ou duas mães, por exemplo, questiona-se, como será realizado o seu registro na Serventia de Registro Civil das Pessoas Naturais?

Quanto à metodologia, foi utilizado o método de abordagem dedutivo, partindo-se de uma visão geral sobre assunto para uma questão particularizada. $\mathrm{O}$ método de procedimento é o monográfico. Também, a técnica de pesquisa utilizada foi a bibliográfica e a documental.

A presente pesquisa foi dividida em três capítulos. No primeiro, aborda-se evolução histórica da família até a sua atual concepção e a afetividade como vínculo formador da entidade familiar na sociedade contemporânea. No segundo, estudase a importância da entidade familiar socioafetiva e a possibilidade de sincronia do vínculo de filiação socioafetivo com o biológico, ou seja, a multiparentalidade. Por fim, o terceiro capítulo é baseado no posicionamento do STF e jurisprudências do Tribunal de Justiça Gaúcho, como também aborda a maneira com que é realizado o registro da multiparentalidade no Registro Civil das Pessoas Naturais.

\subsection{A ENTIDADE FAMILIAR CONTEMPORÂNEA E O AFETO COMO GERADOR DE VÍNCULO DE PARENTALIDADE}

\subsubsection{Um breve histórico sobre a evolução da estrutura da entidade familiar}

A entidade familiar, desde a existência das sociedades mais remotas é reconhecida naturalmente como a base da sociedade, haja vista ter sido a primeira 
forma de agrupamento social e de convivência entre as pessoas. Considera-se, em verdade, a "célula mater" da sociedade. É um microssistema social em que os valores de uma época são reproduzidos de modo a garantir a adequada formação do indivíduo, o que desperta interesse de todos os povos, em todos os tempos, uma vez que entendê-la é preservar a organização e a continuidade da sociedade e do Estado $^{03}$.

Historicamente, a família era composta apenas pelo homem e sua mulher e a prole decorrente daquela união. Esse estrito modelo se dava pelo fato de que a família era formada apenas por pessoas aparentadas entre si pela origem biológica, exceto, é claro, ao casal provedor da prole, que se unia por meio do matrimônio.

Partindo-se de uma análise do Código Civil Brasileiro de 1916, pode-se verificar que, com base naquele texto legislativo, o núcleo familiar dispunha de perfil hierarquizado e patriarcal, onde o pai detinha a função chefe do grupo. Além disso, recebia amparo legal apenas a entidade familiar estabelecida por meio do matrimônio e impossível era a dissolução do casamento. A discriminação, forte traço daquele código, ocorria não somente entre os membros do grupo, submetendo todos ao "pater famílias", como também em relação àquelas uniões não matrimonializadas, das quais advinham filhos denominados ilegítimos. Tudo isso ocorria na tentativa frustrada - de preservar o matrimônio como a única forma legal de se constituir uma família.

O eixo central do Código Civil de 1916 era a tutela do patrimônio, o que moldava, consequentemente, o direito de família. O egoísmo, o patriarcalismo e o autoritarismo presentes no Código refletiam bem a sociedade do século XIX, pois mais importava "ter" do que "ser". Naquela época, a família não era reconhecida como um grupo social afetivamente vinculado, mas como uma unidade econômica dirigida por um chefe ${ }^{04}$.

Entretanto, com o passar dos anos e, considerando as evoluções sociais ocorridas de maneira ampla, as estruturas dos ordenamentos jurídicos voltaram-se à proteção da pessoa humana. As conquistas sociais deram ensejo, por exemplo, à elaboração de Tratados Internacionais de Direitos Humanos, com vista a propiciar valores morais e desenvolvimento de vida digna à pessoa humana.

Desse modo, essas vertentes - voltadas à proteção da pessoa humana - passaram a influenciar diretamente no desenvolvimento da estrutura dos

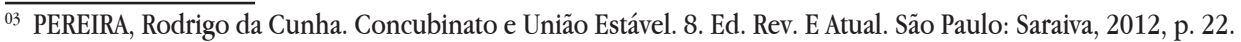

${ }^{04}$ GAGLIANO, Pablo Stolze; PAMPLONA FILHO. Novo curso de direito civil. São Paulo: Saraiva, 2009, p. 45.
} 
ordenamentos jurídicos internos dos países. No Brasil, foram sendo elaboradas diversas leis com o intuito de modificar conteúdos específicos da legislação, eis que dispunham de textos que destoavam com os novos direitos tutelados. O Código Civil de 1916, por exemplo, teve seu texto legal modificado por diversas leis específicas antes de ser substituído pelo novo Código de 2002, dentre as quais se podem citar: o reconhecimento de filhos adulterinos (lei $\mathrm{n}^{\circ} 883$, de 21 de outubro de 1949); o Estatuto da Mulher Casada (lei $n^{\circ} 4.121$, de 27 de agosto de 1962); a Lei do Divórcio (lei $\mathrm{n}^{0} 6.515$, de 26 de dezembro de 1977) etc.

A lei $n^{\circ} 883 / 1949$, revogada pela lei $n^{0} 12.004 / 2009$, tratou, no passado, do reconhecimento de filhos ilegítimos - assim denominados à época, possibilitando a qualquer dos cônjuges o reconhecimento de filhos havidos fora do matrimônio. Isso ocorria porque apenas era possível se constituir família por meio do matrimônio, de modo que as relações havidas fora desse instituto não eram reconhecidas como legítimas e não tinham amparo legal.

O Estatuto da Mulher Casada (lei $\mathrm{n}^{0}$ 4.121/1962) contribuiu ao ordenamento jurídico brasileiro com diversos avanços legislativos. Em síntese, tratou da emancipação feminina em diversas áreas. Acima de tudo, assegurou a plena capacidade à mulher, buscando equipará-la ao homem, em se tratando da vigência da sociedade conjugal. Com isso, o homem perdeu a posição de chefe do grupo familiar, proporcionando ainda mais o desprendimento do direito de família com o patriarcalismo. A partir daí, elevando-se a figura feminina ao mesmo patamar da já havida pelo homem, começou a se reconhecer os direitos de cada indivíduo e sua função no grupo familiar, desbancando-se o "pátrio poder" em face do "poder familiar".

Atualmente, considerando o Estado democrático de Direito e o grande volume de ordenamentos jurídicos positivados, percebe-se que além de continuar sendo concebida como a instituição mais importante do meio social, a família, no Brasil, é expressamente prevista pelo artigo 226 da Constituição Federal de 1988 como sendo a base da sociedade e "objeto" de especial proteção por parte do Estado.

No mesmo contexto, apresentou tratamento igualitário ao homem e à mulher perante a vigência da sociedade conjugal. Mais adiante, no ano de 2010, com a incidência da emenda constitucional $n^{\circ} 66$, foi implementado o parágrafo $6^{\circ}$ no referido artigo, o qual trouxe o divórcio como forma direta para dissolução do casamento. 
Posto isso, dito que passaram a vigorar novos arranjos familiares no país, prevalece tanto na doutrina quanto na jurisprudência o entendimento de que o rol constitucional familiar inserido no artigo 226 da Constituição Federal é exemplificativo e não taxativo. Soma-se a isso, no sentido de inclusão e alargamento de proteção das diversas formas de entidade familiar, o fato de que leis específicas contribuem com conceitos ampliados de família, como no caso da Lei Maria da Penha e na Lei de Adoçã $0^{05}$.

Essa reinterpretação do conceito de família vem ocorrendo, primeiramente, em razão do fator sociocultural, pelo qual a sociedade vive em constante mudança, o que afeta diretamente as estruturas conceituais tidas como modelo pelo ordenamento jurídico. Além disso, atualmente, a família tem por escopo proporcionar a autorrealização de seus componentes, contribuindo com relações de afeto recíproco e concretizando-se de uma forma que os familiares possam contar com apoio mútuo dos demais, razão pela qual a convivência passou a se dar por meio de um "querer" e não mais por um "necessitar".

Com isso, além dos dois contornos familiares catalogados pela Carta Maior união estável e a entidade familiar monoparental -, e do tido como conceito exclusivo por tempos - matrimonial -, há que se afirmar a existência de algumas outras modalidades de entidades familiares reconhecidas por manifestações doutrinárias.

Maria Berenice Dias ${ }^{06}$ corrobora que na sociedade contemporânea é do conhecimento de todos a existência de arranjos familiares que se distanciam do modelo "tradicional". Os ideais de pluralismo, solidarismo, democracia, igualdade, liberdade e humanismo se voltaram à proteção da pessoa humana, havendo o resgate do ser humano como sujeito de direito, razão pela qual a família adquiriu função instrumental para a melhor realização dos interesses afetivos e existenciais de seus componentes.

Posto isso, considera-se que uma das grandes evoluções do pensamento acerca do direito das famílias foi ter trazido a compreensão de que a família não é um fato da natureza, mas sim da cultura. Com isso, considerando que é um fato cultural, pode sofrer variações de acordo com o tempo e o espaço. Ou seja, cada sociedade, bem como cada cultura podem construir diferentes formas de família. Em razão disso,

\footnotetext{
${ }^{05}$ TARTUCE, Flávio. Manual de direito civil: volume único. 6. ed. rev., atual. e ampl. Rio de Janeiro: Forense; São Paulo: Método, 2016. p. 1203.

${ }^{06}$ DIAS, Maria Berenice. Manual de direito das famílias - 10. ed. rev., atual. e ampl. São Paulo: Revista dos Tribunais, 2015, p. 130.
} 
pode-se afirmar que o instituto da família passou por grandes evoluções ao longo do tempo, desprendendo-se dos moldes completamente restritivos e apresentando-se, atualmente, em modelos mais modernos e flexíveis. ${ }^{07}$

\subsubsection{Entidade familiar contemporânea: $O$ afeto como gerador de vínculo de parentalidade}

Toda a modificação ocorrida no âmbito familiar, conforme acima delineado, se deu pela valorização de um fator que há muito vinha reformulando as relações interpessoais, qual seja, o afeto. Em decorrência do enaltecimento da pessoa humana em detrimento do patrimônio, surgiram, ao ordenamento jurídico, novos coeficientes a serem analisados quando da prestação da tutela jurisdicional pelo legislador como, por exemplo, o da realização pessoal do indivíduo, atrelado, diretamente, à dignidade da pessoa humana. Com efeito, em se tratando desse assunto, nada mais comum do que se falar em parentalidade, haja vista que as relações de parentesco são concebidas diretamente a partir do sistema familiar.

Em síntese, atualmente as relações interpessoais têm por base a identificação de uma determinada pessoa com outra pela coincidência de interesses, e não mais pelo fato de se verificarem vantagens econômicas ou o suprimento de necessidades financeiras. Com isso, o vínculo afetivo passou a ser, sobretudo, o fator que determina a solidificação de uma entidade familiar.

Nesse sentido, merecem destaque as palavras da juspsicanalista Giselle Câmara Groeninga, para quem

O papel dado à subjetividade e à afetividade tem sido crescente no Direito de Família, que não mais pode excluir de suas considerações a qualidade dos vínculos existentes entre os membros de uma família, de forma que possa buscar a necessária objetividade na subjetividade inerente às relações. Cada vez mais se dá importância ao afeto nas considerações das relações familiares; aliás, um outro princípio do Direito de Família é o da afetividade" ${ }^{\text {8 }}$

Entende-se que o vínculo determinante para a solidificação de uma família é

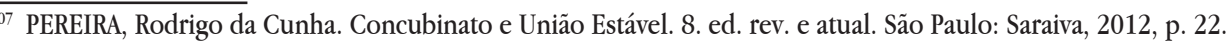

${ }^{08}$ GROENINGA, Giselle Câmara. Direito Civil. Vol. 7. Direito de Família. HIRONAKA, Giselda M. F Novaes; BARBOSA, Aguida Arruda; VIEIRA, Cláudia Stein (Coord). São Paulo: RT, 2008, p. 47-52.
} 
a vontade recíproca de ter-se por perto, de querer-se bem e considerar-se aparentado. Como bem pontua a juspsicanalista, é por meio da subjetividade que os sentimentos se afeiçoam e promovem a concepção do grupo familiar, diante da coincidência de interesses, independentemente, portanto, da existência de vínculo biológico entre os indivíduos.

Diante das mais variadas estruturas familiares havidas atualmente, a estrutura central e essencial das famílias é proporcionar o amor e a felicidade entre seus membros, tudo em função da autorrealização pessoal. É nesse sentido que se pode afirmar que, assim como o matrimônio imperou como elemento constituidor do grupo familiar, hoje quem impera nessas relações é o fenômeno da afetividade.

Sobre a família contemporânea, no ano de 1993, Michelle Perrot ${ }^{09}$ já afirmava que

Não é a família em si que nossos contemporâneos recusam, mas o modelo excessivamente rígido e normativo que assumiu o século XIX. Eles rejeitam o nó, não o ninho. A casa é, cada vez mais, o centro da existência. O lar oferece, num mundo duro, um abrigo, uma proteção, um pouco de calor humano. [...] $\mathrm{O}$ que se gostaria de conservar da família, no terceiro milênio, são seus aspectos positivos: a solidariedade, a fraternidade, a ajuda mútua, os laços de afeto e amor.

Ocorre que, por vezes, a simultaneidade desses vínculos não se encontra personificada somente em uma pessoa, como é nos casos em que o indivíduo possui padrasto ou madrasta, ou, usualmente, "pai/mãe (s) de coração". Diante disso é que há a necessidade de se compreender que, mesmo possuindo o vínculo biológico, é fato que a pessoa pode criar vínculo de identidade paterna ou materna com pessoa diversa daquela com que possui o vínculo consanguíneo, como ocorre nos casos das entidades familiares recompostas fundadas na afetividade.

Remetendo o estudo às vertentes constitucionais, sabe-se que somente com o advento da Constituição Federal de 1988 é que as estruturas familiares contemporâneas passaram a ter valor jurídico. As uniões estáveis, por exemplo, somente não possuíam valor jurídico porque o Código Civil de 1916 era extremamente conservador, patriarcal e patrimonialista e a única forma de se constituir uma família, até então, se dava por meio do matrimônio.

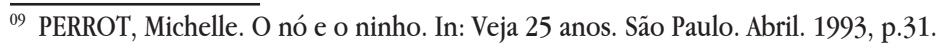


Pode-se dizer que os demais arranjos familiares, não consolidados pelo matrimônio, eram considerados ilícitos. A partir do momento em que as unióes matrimonializadas deixaram de ser reconhecidas como a única base da sociedade, aumentou o espectro da família ${ }^{10}$.

Para Maria Berenice Dias ${ }^{11}$ é no direito da família onde mais se sente o reflexo dos princípios que a Constituição Federal consagra como valores sociais fundamentais, e que não podem se distanciar da atual concepção da família, com sua feição desdobrada em múltiplas facetas. Existem princípios especiais que são próprios das relações familiares e devem servir de norte na hora de apreciar qualquer relação que envolva questões de família, despontando, dentre eles, os princípios da solidariedade e da afetividade.

Em razão disso, levando-se em conta que a sociedade contemporânea é pluralista, a família também o deve ser para todos os fins. Assim, surge um novo fato determinante para as relações familiares, que é o fenômeno da afetividade, como formador dessas relações e objeto de proteção estatal, não sendo mais o caráter biológico o critério exclusivo na formação do vínculo familiar.

Atualmente, o afeto é o principal fator que deve ser estudado no direito de família. As relações familiares são permeadas, acima de tudo, pela convivência e pelo cuidado, de modo que a mera ligação biológica tornou-se fator insuficiente para determinar a existência de uma família.

No entendimento de Paulo Roberto Iotti Vecchiatti ${ }^{12}$,

A evolução social quanto à compreensão da família elevou o afeto à condição de princípio jurídico oriundo da dignidade da pessoa humana no que tange às relações familiares, visto que estas, para garantirem o direito à felicidade e a uma vida digna (inerentes à dignidade humana), precisam ser pautadas pelo afeto e não por meras formalidades como a do casamento civil. Assim, o princípio do afeto é um princípio constitucional implícito, decorrente da dignidade da pessoa humana e, ainda, da própria união estável, que tem nele o principal elemento para o reconhecimento do status jurídico-familiar de uniões

\footnotetext{
${ }^{10}$ DIAS, Maria Berenice. Manual de direito das famílias. 10. ed. rev., atual. e ampl. São Paulo: Revista dos Tribunais, 2015, p. 49.

${ }^{11}$ DIAS, Maria Berenice. Manual de direito das famílias -10. ed. rev., atual. e ampl. São Paulo: Revista dos Tribunais, 2015, p. 43.

12 VECCHIATTI, Paulo Roberto Iotti. Manual da Homoafetividade: possibilidade jurídica do casamento civil, da união estável e da adoção por casais homoafetivos. Rio de Janeiro: Forense; São Paulo: Método, 2008, p. 221.
} 
não-matrimonializadas.

A família é o primeiro grupo social com o qual o indivíduo tem contato na sua vida. Por meio dele, o indivíduo vai formar seu caráter, entender o que é certo e errado, aprender a ser honesto, bem como a viver em sociedade. Da mesma forma com que o matrimônio - em um período histórico totalmente patriarcal e patrimonialista - foi visto como a única forma de constituição de família, hoje, diante das mais variadas formas de arranjos familiares, foi dado ao afeto o papel potencializador de constituir-se uma família.

Para Heraldo Pessoa Souto Maior, em um estudo acerca do pensamento de Durkheim sobre a família, a entidade familiar não pode ser tratada superficialmente, mas com a profundidade e complexidade intrínsecas à sua conexão com a estrutura social.

Para a ciência, os seres não estão uns acima dos outros; são apenas diferentes porque seus ambientes diferem. Não há uma maneira de ser e viver melhor para todos, com a exclusão de qualquer outra, e, por conseguinte, não é possível classificálas hierarquicamente segundo se aproximem ou distanciem desse ideal único. [...] A família de hoje não é mais nem menos perfeita que a de antigamente: ela é outra porque as circunstâncias são diferentes. [...] O cientista estudará então cada tipo em si mesmo e sua única preocupação será a de procurar a relação que existe entre os caracteres constitutivos desse tipo e as circunstâncias que os cercam ${ }^{13}$.

A partir dessa percepção, tem-se que todas as alterações que ocorreram no âmbito familiar obviamente se refletem nos vínculos de parentesco. Ademais, outros acontecimentos - além do mero desprendimento patrimonialista e patriarcal - influenciaram essas modificações.

Com a evolução da engenharia genética, por exemplo, e o surgimento das mais diversas formas de reprodução assistida, os vínculos de parentesco não poderiam ficar limitados à verdade biológica. A própria Constituição Federal (art. 227, § $6^{\circ}$ ) encarregou-se de alargar o conceito de entidade familiar ao não permitir distinções entre filhos. Ocorreu verdadeira desbiologização da paternidade-maternidadefiliação e, consequentemente, do parentesco em geral. Nesse mesmo sentido é o que

13 SOUTO MAIOR, Heraldo Pessoa. Durkheim e a família: Da "Introdução à Sociologia da Família" à "Família Conjugal”. Revista ANTHROPOLÓGICAS, ano 9, v. 16, n. 1, p. 7-30, 2005. Disponível em: https://periodicos. ufpe.br/revistas/revistaanthropologicas/article/viewFile/23622/19277 Acesso em: 13/10/2017. 
ocorre com as entidades familiares contemporâneas, onde a afetividade tem o mais relevante papel jurídico. Assim, deve-se buscar um conceito plural de paternidade, de maternidade e de parentesco ${ }^{14}$.

\section{POSSIBILIDADE DE SINCRONIA DAS FILIAÇÕES BIOLÓGICA E SOCIOAFETIVA: A MULTIPARENTALIDADE}

\subsection{O PAPEL DA FILIAÇÃO SOCIOAFETIVA}

Acredita-se que a possibilidade do reconhecimento legal da paternidade socioafetiva está inserida no art. 1.593 do Código Civil, o qual afirma que "o parentesco é natural ou civil, conforme resulte de consanguinidade ou outra origem". O parentesco pode ser conceituado pelo vínculo biológico, do vínculo da afinidade e, ainda, do vínculo civil.

Posto isso, denota-se que é pelo parentesco civil, com a denominada parentalidade socioafetiva, onde se verifica a incidência do fator afeto como formador de relações familiares. Além disso, para a caracterização de uma relação de socioafetividade é necessário observar requisitos de existência desse vínculo. A filiação socioafetiva decorre da posse do estado de filho e corresponde à vontade aparente.

Como bem pontua Maurício Bunazar, "a partir do momento em que a sociedade passa a encarar como pais e/ou mães aqueles perante os quais se exerce a posse do estado de filho, juridiciza-se tal situação [... ${ }^{\prime 15}$. De todo modo, com base no que já foi estudado e considerando que leis mais recentes ostentam o conceito de família com vista à valorização do afeto e interação existente entre as pessoas, qualquer projeto de lei que procure restringir o conceito de família é visto como inconstitucional, como é o caso do Estatuto da Família, de autoria do deputado Anderson Ferreira (PR-PE), em trâmite no Congresso Nacional.

O texto do PL6583/2013, que não trata o assunto da melhor forma, reconhece como família apenas "a entidade familiar formada a partir da união entre um homem e uma mulher, por meio de casamento ou de união estável, e a comunidade formada

\footnotetext{
14 GAMA, Guilherme Calmon Nogueira da. Das relações de parentesco. ln: DIAS, Maria Berenice; PEREIRA, Rodrigo da Cunha (coord.). Direito de família e o novo Código Civil. 3. ed. Belo Horizonte: Dei Rey, 2003, p. 107.

${ }^{15}$ BUNAZAR, Maurício. Pelas portas de Villela: um ensaio sobre a pluriparentalidade como realidade sóciojurídica. Revista IOB de Direito de Família, Porto Alegre: Síntese, n. 59, p. 63-73, abr./maio 2010, p. 67.
} 
por qualquer dos pais e seus filhos". Ocorre que, a Constituição Federal, ao garantir especial proteção à família, estabeleceu as diretrizes do direito das famílias em grandes eixos, a saber: (a) a igualdade entre homens e mulheres na convivência familiar; (b) o pluralismo das entidades familiares merecedoras de proteção; e (c) o tratamento igualitário entre todos os filhos.

Sendo assim, essas normas, por serem direito subjetivo com garantia constitucional, servem de obstáculo a que se operem retrocessos sociais, o que configuraria verdadeiro desrespeito às regras constitucionais. Desse modo, quando é alcançado determinado grau de concretização de uma norma constitucional definidora de direito social, fica o legislador proibido de suprimir ou reduzir os direitos definidos por ela ${ }^{16}$.

Com efeito, demonstrada a possibilidade de parentesco pela socioafetividade, resta salientar que possui mesmo valor jurídico do atribuído ao parentesco biológico. Ainda, nesse sentido, é importantíssimo referir que nem sempre a existência de um vínculo excluirá o outro, haja vista que é bem possível suas existências simultâneas, o que dá ensejo ao vínculo da multiparentalidade, objeto de análise do presente trabalho.

\subsection{A EXPECTATIVA DE RECONHECIMENTO DA MULTIPARENTALIDADE}

De início, é importante mencionar que a possibilidade jurídica da multiparentalidade somente surgiu no cenário jurídico brasileiro com vista a efetivar relações familiares existentes de fato, tendo em vista que, atualmente, o vínculo que consuma as relações familiares é, sobretudo, o afetivo. Contudo, a própria essência da multiparentalidade demonstrará que o laço afetivo não necessariamente afastará o biológico, podendo ocorrer a coexistência de ambos, com a devida inscrição registral.

Constata-se, portanto, que a multiparentalidade (dupla parentalidade; pluriparentalidade) se caracteriza pela admissão de o indivíduo ter dois vínculos de filiação distintos declarados em seu registro de nascimento, decorrentes da coexistência dos vínculos socioafetivo e biológico. Com efeito, afasta-se a regra de se fazer uma escolha entre a prevalência de quaisquer dos vínculos, como

${ }^{16}$ DIAS, Maria Berenice. Manual de direito das famílias. 10. ed. rev., atual. e ampl. São Paulo: Revista dos Tribunais, 2015, p. 51. 
anteriormente foi necessário.

Além disso, o tratamento dispensado pelo legislador ao direito de família em geral requer a constante modificação e adequação às realidades vividas extrajudicialmente, pois, por regular manifestações sociais e culturais em constante modificação, depende de remodelação contínua, absorvendo a realidade fática ao invés de impor modelos criados ideologicamente.

Evidencia-se, previamente, que a expectativa da multiparentalidade passou a ter possibilidade jurídica a partir de decisões proferidas por juízes e Tribunais assestados da necessidade de promover o adequado julgamento ao caso concreto, deslocando-se além da própria legislação pré-existente, passando a buscar em princípios constitucionais e gerais do direito à sustentação de suas manifestações, como forma de reafirmar e solidificar a dignidade da pessoa humana e a preservação do melhor interesse da criança e do adolescente.

Ao corroborar o exposto acima, no ano de 2012 o Tribunal de Justiça do Estado de São Paulo proferiu decisão inédita, determinando o registro da madrasta como mãe civil de enteado, mantendo-se a mãe biológica:

MATERNIDADE SOCIOAFETIVA Preservação da Maternidade Biológica Respeito à memória da mãe biológica, falecida em decorrência do parto, e de sua família - Enteado criado como filho desde dois anos de idade Filiação socioafetiva que tem amparo no art. 1.593 do Código Civil e decorre da posse do estado de filho, fruto de longa e estável convivência, aliado ao afeto e considerações mútuos, e sua manifestação pública, de forma a não deixar dúvida, a quem não conhece, de que se trata de parentes - A formação da família moderna nãoconsanguínea tem sua base na afetividade e nos princípios da dignidade da pessoa humana e da solidariedade Recurso provido.

A partir dessas primeiras manifestações - estritamente promovidas com vista a preservar os reais interesses dos indivíduos abarcados por relações multiparentais -, encaminhou-se à repersonalização do direito de família e, consequentemente, do ireito civil. Por ser um assunto ainda não consolidado juridicamente, surge como gerador de divergência doutrinária e, consequentemente, de decisões judiciais. A configuração da filiação socioafetiva ocorre quando pessoas que não possuem 
vínculos consanguíneos consideram-se como pais e filhos e buscam, por meio do Poder Judiciário, o reconhecimento legal dessa situação. De todo modo, o vínculo socioafetivo pode ser declarado pela sentença sem que exclua o vínculo biológico pré-existente, fazendo com que, dessa maneira, ocorra a cumulação da filiação biológica com a socioafetiva, decorrendo daí a multiparentalidade.

De antemão, sabe-se que a "multiparentalidade de fato" é uma ocorrência comum hodiernamente. A existência de entidades familiares reconstituídas, em que os cônjuges dos genitores do indivíduo assumem o papel de "pais e mães de coração" é muito mais comum do que se imagina. Entretanto, os casos levados ao Poder Judiciário ainda são raros, até mesmo pelo fato de que, grande parte da sociedade acredite que esses vínculos familiares não possuem a devida tutela do Estado. Isso ocorre pelo fato de que, considerando que o engessamento do conceito de entidade familiar perdurou por muitos anos, esse recente alargamento conceitual deve se manter instável ainda por certo tempo.

Além do mais, já há evidências na legislação no sentido de se estreitar o vínculo entre enteado e padrasto/madrasta, conforme se pode verificar do conteúdo da lei $\mathrm{n}^{0} 11.924 / 2009$. A lei $\mathrm{n}^{0} 11.924$, de 17 de abril de 2009, alterou o artigo 57 da lei $\mathrm{n}^{\mathrm{0}}$ 6.015/1973 (Lei de Registros Públicos), passando a autorizar o enteado ou a enteada a adotar o nome da família do padrasto ou da madrasta. Nota-se, com isso, que no ano de 2009 já se reconhecia a estreita relação havida entre padrasto/ madrasta e os enteados. Salienta-se que o projeto de lei (PL 206/7), do qual resultou a lei $\mathrm{n}^{0} 11.924 / 2009$, foi elaborado pelo deputado paulista Clodovil Hernandes, do partido $\mathrm{PR} / \mathrm{SP}$, com o intuito de exteriorizar situação fática pré-existente no seio familiar, conforme por ele justificado.

Nesse sentido, pode-se afirmar que a multiparentalidade vai além da simples possibilidade de se adicionar o sobrenome do padrasto/madrasta ao nome do enteado. Por ser mais ampla, abrange outras questões, além da registral, pois estende os direitos que a pessoa teria, em tese, provenientes de relações de parentesco com um pai e uma mãe, para além disso, seja na duplicidade de ambos os genitores, ou na presença de apenas um deles.

Ademais, embora a doutrina e jurisprudência brasileiras já reconheçam a existência jurídica do vínculo da multiparentalidade, a legislação registral ainda carece de elaboração. Assim, a pessoa que busca o reconhecimento da multiparentalidade ainda é obrigada a buscar amparo perante o Poder Judiciário. 
Por suposto, considerando o fato de que a ausência de legislação não é pretexto para impossibilidade jurídica do pedido, a jurisprudência vem sendo a maior aliada das decisões que reconhecem a existência do vínculo da multiparentalidade. Posto isso, verifica-se que a multiparentalidade surgiu para efetivar as relações existentes no mundo fático. Partindo do princípio do livre planejamento familiar, e tendo em vista que atualmente é o princípio da afetividade que rege a família, nada mais justo que possibilitar o registro dessas relações. $O$ vínculo afetivo entre um adulto e uma criança muitas vezes se sobressai em relação ao vínculo biológico. Não é o DNA que torna alguém pai ou mãe; apenas comprova as origens biológicas da criança.

Posto isso, já que a filiação biológica é aquela havida "naturalmente" e a filiação socioafetiva "foi" reconhecida pelo ordenamento pátrio, não há que se questionar a validade do princípio da afetividade para a solidificação e reconhecimento da multiparentalidade, somente pelo fato de que, aqui, apenas se procede a soma de dois tipos legais de filiação, dando segurança e validade jurídica ao cotidiano de certas famílias, tudo com a magnífica função voltada a defender o melhor interesse da criança e do adolescente e, não menos importante, da dignidade da pessoa humana.

\section{A MULTIPARENTALIDADE E O POSICIONAMENTO DOS TRIBUNAIS: A SOLIDIFICAÇÃO DA MULTIPARENTALIDADE POR MEIO DO REGISTRO CIVIL}

\subsection{O POSICIONAMENTO DO SUPREMO TRIBUNAL FEDERAL E O ENTENDIMENTO JURISPRUDENCIAL DO TRIBUNAL DE JUSTIÇA DO RIO GRANDE DO SUL PELA SOLIDIFICAÇÃO DA MULTIPARENTALIDADE}

Recentemente houve a aprovação, pelo Supremo Tribunal Federal, de relevante tema sobre direito de família. O julgado, que teve repercussão geral conhecida, abaixo analisado, e deve nortear outras decisões nos tribunais de todo país, dispõe sobre os contornos familiares contemporâneos e o reflexo desses novos arranjos nas relações de parentesco e, especialmente, de filiação, no ordenamento jurídico brasileiro.

Em sessão realizada na data de 21 de setembro 2016, o Supremo Tribunal Federal aprovou importantíssimo tema em relação às categorias de filiação e 
parentesco. O "leading case" trata do reconhecimento jurídico da multiparentalidade (ou pluriparentalidade). A Ação RE 898060-SC, que tratara da prevalência ou equiparação da filiação socioafetiva em relação à biológica, acabou por considerar a equiparação de ambos os vínculos parentais.

O tema de Repercussão Geral n ${ }^{\circ} 622$, de relatoria do ministro Luiz Fux, foi aprovado com o seguinte teor: "A paternidade socioafetiva, declarada ou não em registro público, não impede o reconhecimento do vínculo de filiação concomitante baseado na origem biológica, com os efeitos jurídicos próprios".

A tese é explícita em afirmar a possibilidade de sincronia de uma filiação socioafetiva concomitantemente com uma filiação biológica, mantendo-se ambas em determinado caso concreto [...]. Por meio disso, a equiparação das duas modalidades de filiação em mesmo patamar social faz com que inexista qualquer hierarquia entre elas. Com essa decisão, o Supremo Tribunal Federal acabou por reconhecer a possibilidade jurídica da pluralidade de vínculos familiares e, por suposto, da multiparentalidade ${ }^{17}$.

O ministro relator, Luiz Fux, em explanação utilizada para embasar seu posicionamento diante do caso e proferir seu voto, destacou, por imperioso, a omissão legislativa em que repousam as bases do direito de família no Brasil, diante da pluralidade de arranjos familiares. O Tribunal de Justiça do Estado do Rio Grande do Sul tem se manifestado nessa mesma perspectiva, qual seja, de considerar a existência de entidades familiares aquém daquelas inseridas no rol do artigo $226 \mathrm{da}$ Constituição Federal, as quais possuem estrita conexão com a afetividade e estimulam o alargamento dos vínculos de filiação. Corroborando o exposto, o presente acórdão ${ }^{18}$, proferido pelo Tribunal de Justiça Gaúcho, demonstra a possibilidade do reconhecimento da multiparentalidade "post mortem".

Nota-se que, nesse caso, o requerente buscou o reconhecimento da filiação biológica após o falecimento do suposto pai biológico, contudo, sem a exclusão da paternidade registral. Depois de realizado exame de DNA, constatou-se a filiação biológica entre requerente e requerido. Ao final, decidiu-se por manter a paternidade registral, por se tratar de parentalidade socioafetiva, somando-se, contudo, à paternidade biológica. O requerente foi beneficiado com o vínculo

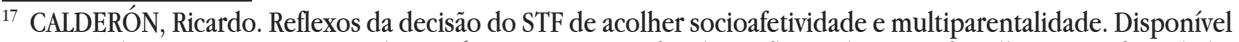
em http://www.conjur.com.br/2016-set-25/processo-familiar-reflexos-decisao-stf-acolher-socioafetividademultiparentalidade\#_ftn2. Acesso em 07/10/2016.

${ }^{18}$ RIO GRANDE DO SŪL. Apelação Cível No 70071692057, Oitava Câmara Cível, Tribunal de Justiça do RS, Relator: Rui Portanova, Julgado em 27/04/2017.
} 
da multiparentalidade e todos os efeitos decorrentes dessa nova modalidade de filiação ${ }^{19}$. Ocorre que, em primeiro grau, na supracitada sentença, a mesma acabou por negar o reconhecimento do vínculo biológico, em vista de que somente seria possível por iniciativa do suposto pai, contudo, já falecido. Em sede de apelação, acabou o TJRS por prover o recurso, de modo que, após perícia técnica no sentido de se comprovar a paternidade biológica, reconheceu o vínculo biológico "post mortem" e determinou a inclusão do pai biológico no registro de nascimento do menor, em conjunto com o pai registral, ou melhor, socioafetivo, bem como dos avós biológicos paternos, ora autores da mesma ação. Veja-se aqui, portanto, um caso notório de multiparentalidade.

Do mesmo modo, noutro caso, o Tribunal de Justiça gaúcho reconheceu a existência do vínculo da multiparentalidade em arranjo familiar homoafetivo. Desta vez, o processo judicial tramitou na Comarca de Porto Alegre-RS e foi julgado extinto sem resolução de mérito diante da impossibilidade jurídica do pedido.

$\mathrm{Na}$ presente demanda, figurou como requerente um casal homoafetivo formado por duas mulheres e um amigo do casal. Após longo planejamento familiar, houve a concepção da criança, filha biológica do "amigo do casal" e cuja gestação competiu a uma das mulheres. Ajuizaram uma ação requerendo o registro da criança em nome dos três, a qual foi extinta sem resolução de mérito. Ocorre que as partes interpuseram recurso de apelação, o qual foi provido, nos seguintes termos:

APELAÇÃO CÍVEL. DECLARATÓRIADE MULTIPARENTALIDADE. REGISTRO CIVIL. DUPLA MATERNIDADE E PATERNIDADE. IMPOSSIBILIDADE JURÍDICA DO PEDIDO. INOCORRÊNCIA. JULGAMENTO DESDE LOGO DO MÉRITO. APLICAÇÃO ARTIGO 515, § $3^{\circ}$ DO CPC. [...] Da mesma forma, há que se julgar a pretensãoda parte, a partir da interpretação sistemática conjunta com demais princípios infra-constitucionais, tal como a doutrina da proteção integral o do princípio do melhor interesse do menor, informadores do Estatuto da Criança e do Adolescente (Lei 8.069/90), bem como, e especialmente, em atenção do fenômeno da afetividade, como formador de relações familiares e objeto de proteção Estatal, não sendo o caráter biológico o critério exclusivo na formação de vínculo familiar. Caso em que no plano fático, é flagrante o ânimo

${ }_{19}$ RIO GRANDE DO SUL. Apelação Cível No 70071692057, Oitava Câmara Cível, Tribunal de Justiça do RS, Relator: Rui Portanova, Julgado em 27/04/2017. 
de paternidade e maternidade, em conjunto, entre o casal formado pelas mães e do pai, em relação à menor, sendo de rigor o reconhecimento judicial da "multiparentalidade", com a publicidade decorrente do registro público de nascimento. DERAM PROVIMENTO. (SEGREDO DE JUSTIÇA) ${ }^{20}$.

Constata-se, mais uma vez, o reconhecimento do vínculo da multiparentalidade no Estado do Rio Grande do Sul, dessa vez por relatoria do desembargador José Pedro de Oliveira Eckert. Para o desembargador, a situação fática desse grupo familiar não somente fez com que se julgasse o mérito do processo, extinto por impossibilidade jurídica do pedido em primeiro grau, como também analisou e reafirmou a entidade familiar contemporânea e a pluralidade de vínculos parentais decorrentes dessas uniões. Ainda mais, ratificou a necessidade de se exteriorizar juridicamente essas situações, com a devida inscrição registral.

Ainda em se tratando de decisões judiciais ocorridas no território do Estado do Rio Grande do Sul, agora em juízo de primeiro grau, é de se mencionar a sentença proferida pela Exma. Sra. Dra. Juíza de Direito, Carine Labres, concedendo o vínculo da multiparentalidade. O processo tramitou na Vara Judicial da Comarca de São Francisco de Assis-RS e teve o pedido formulado na inicial julgado procedente. No caso, os autores requereram a declaração da multiparentalidade em benefício de dois menores, os quais sofreram a perda da genitora biológica e passaram a conviver, desde então, com a nova companheira de seu pai, a qual passaram a ter por "mãe de coração".

No caso em comento, após longa instrução probatória, foi verificada a existência de fortes laços afetivos entre a mãe socioafetiva e os filhos. Posto isso, infere-se que mesmo havendo omissão legislativa nesse assunto, o Poder Judiciário não se eximiu do julgamento e buscou melhores soluções às situações apresentadas. É a multiparentalidade um reflexo dos elos de parentalidade gerados pelo crescente reconhecimento da existência legal de entidades familiares recompostas. Necessário, ainda se observar que a multiparentalidade somente vem a efetivar situações costumeiras no cotidiano de muitos indivíduos. Nesse sentido que deve obrar o legislador, de buscar respostas fora do ordenamento jurídico - seja na sociologia, na psicologia, ou até mesmo na filosofia -sempre que assim o for insuficiente, ou,

${ }^{20}$ RIO GRANDE DO SUL. Apelação Cível No 70062692876, Oitava Câmara Cível, Tribunal de Justiça do RS, Relator: José Pedro de Oliveira Eckert, Julgado em 12/02/2015. 
mesmo que suficiente, já destoe com as realidades sociais.

3.2 REGISTRO CIVIL DAS PESSOAS NATURAIS DO ESTADO DO RIO GRANDE DO SUL: O PROCEDIMENTO REGISTRAL DA MULTIPARENTALIDADE

Incontroversa a possibilidade jurídica da multiparentalidade, resta analisar a exteriorização dessa modalidade de filiação. O Registro Civil das Pessoas Naturais, conforme disposto no artigo $1^{\circ}, \S 1^{\circ}$, inciso I, da lei $\mathrm{n}^{\circ} 6.015 / 73$, faz parte dos serviços concernentes aos Registros Públicos. Estes, por sua vez, tem a função de condicionar autenticidade, segurança e eficácia aos atos e negócios jurídicos a cada vez que realizados. Inicialmente, convém ressaltar a importância dos registros públicos. Registrar um ato ou negócio significa prevenir-se contra questionamentos inconvenientes e lesivos a direitos conquistados, bem como contra efetivos danos a esses direitos. Nas palavras de Carlos Renato de Oliveira C. Leão ${ }^{21}$, o "sentido geral da existência de registros públicos está em tornar públicos os atos e negócios, fazer o controle da sua legalidade e ainda conservar seus detalhes, pelo tempo que for necessário"

Toda vez que, a partir de um ato ou negócio, se faça surgir um direito a determinado titular, é necessário que seja formalizado com o seu devido registro, sob pena de não se fazê-lo valer e/ou trazê-lo eficácia. Segundo a doutrina de Maria Helena Diniz ${ }^{22}$, fato jurídico "é o acontecimento, previsto em norma jurídica, em razão do qual nascem, se modificam, subsistem e se extinguem relações jurídicas". Como bem pontua Álvaro Villaça Azevedo ${ }^{23}$, no negócio jurídico "as partes interessadas, ao manifestarem sua vontade, vinculam-se e estabelecem por si mesmas, normas regulamentadoras de seus próprios interesses".

Assim, as atividades notariais e registrais constituem função do Estado, conforme disposto no artigo 236, "caput", da Constituição Federal: "Os serviços notariais e de registro são exercidos em caráter privado, por delegação do Poder Público"24. Contudo, verifica-se que o Estado não atua diretamente nas searas notarial e registral, haja vista a determinação legislativa de delegar essa função a um

${ }^{21}$ IRTDPJ BRASIL. Conheça um pouco da importância do registro público na vida do cidadão. Disponível em: http://www.irtdpjbrasil.com.br/NEWSITE/Registro\%20Publico\%20x\%20Cidadania.pdf_Acesso em: 12/12/2017.

${ }^{22}$ DIAS, Maria Berenice. Manual de direito das famílias. 10. ecl. rev., atual. e ampl. São Paulo: Editora Revista dos Tribunais, 2015, p. 399.

${ }^{23}$ AZEVEDO, Álvaro Villaça. Código Civil comentado. São Paulo: Atlas 2003, p. 346.

${ }^{24}$ BRASIL. Constituição da República Federativa do Brasil de 1988, de 05 de outubro de 1988. Presidência da República. Disponível em: http://www.planalto.gov.br/ccivil_03/constituicao/constituicaocompilado.htm. Acesso em 03/10/2017. 
particular.

Os particulares que exercem essa função pública delegada pelo Estado são profissionais de direito denominados notários e registradores - ou tabelião e oficial de registro, respectivamente-, dependendo da área a que estão legitimados a atuar, muito embora essas atividades sejam desempenhadas em caráter privado, sem que esses profissionais integrem o corpo orgânico do Estado.

Com efeito, demonstrada a função essencial dos registros públicos, a qual, em síntese, tem o escopo de proporcionar segurança, publicidade, validade e eficácia aos atos jurídicos (art. $1^{\circ}$, "caput”, da lei $n^{\circ}$ 6.015/73), registra-se a divisão entabulada pela lei dos Registros Públicos, qual seja: "§ $1^{\circ}$ Os Registros referidos neste artigo são os seguintes: I - o registro civil de pessoas naturais; II - o registro civil de pessoas jurídicas; III - o registro de títulos e documentos; e IV - o registro de imóveis" ${ }^{25}$.

A lei federal $n^{\circ}$ 6.015, também conhecida como Lei de Registros Públicos, em vigor desde 31 de dezembro de 1973, dispõe sobre os registros públicos e delibera, em seu Título II, sobre o "Registro das Pessoas Naturais". É com base nesse texto legislativo que se verificará a maneira com que será realizado o registro da multiparentalidade. Senão vejamos.

O Registro Civil das Pessoas Naturais (RCPN), como seu próprio nome indica, tem como foco de interesse a pessoa física ou natural. Tem por finalidade o registro de atos ligados a momentos importantes na vida de uma pessoa. Nessas serventias são registrados, principalmente, o nascimento, o casamento e o óbito. Além disso, podem ser também averbadas separações, divórcios, emancipações, interdições, as sentenças declaratórias e demais atos envolvendo a pessoa natural ${ }^{26}$.

Corroborando o exposto, Luiz Guilherme Loureiro ${ }^{27}$ preleciona que

Nesse contexto, o registro tem por função fixar o estado civil ou estado de família da pessoa natural, provando seu nome, filiação, sua idade e capacidade para os atos da vida civil, o casamento ou a viuvez, entre outros fatos e atos

\footnotetext{
$\overline{25}$ BRASIL. Lei 6.015, de 31 de dezembro de 1973. Disponível em: http://www.planalto.gov.br/ccivil_03/leis/ L6015original.htm. Acesso em 14/05/2017.

${ }^{26}$ ASSOCIAÇÃO DOS NOTÁRIOS E REGISTRADORES DO BRASIL. Qual a função do Cartório de Registro Civil? Disponível em: https://blog.cartorio24horas.com.br/qual-a-funcao-do-registro-civil-das-pessoas-naturais. Acesso em 12/09/2017.

${ }^{27}$ LOUREIRO, Luiz Guilherme. Registros públicos: teoria e prática. 5. ed. rev., atual e ampl. Rio de Janeiro: Forense; São Paulo: MÉTODO, 2014, p. 32.
} 
importantes para a identificação e proteção da pessoa natural e para sua vida jurídica e social. (Grifo nosso).

É por meio desses registros que os direitos e situações jurídicas decorrentes dos fatos e atos jurídicos em sentido amplo, e que interessam a toda sociedade, são tornados públicos e, dessa forma seus efeitos podem ser oponíveis em face de terceiros de boa fé.

Então vejamos. O artigo 50, "caput", da lei n 6.015/73 dispõe que "todo nascimento que ocorrer no território nacional deverá ser dado a registro, no lugar em que tiver ocorrido o parto ou no lugar da residência dos pais [...]"28.

Destarte, aqui, não se fará uma análise muito aprofundada acerca do procedimento de registro de nascimento. O que nos interessa, nesse momento, é ter a compreensão de que, embora registrado com base em documentos e informações que à época o trazia validade, o assento de nascimento pode ter seu conteúdo modificado sempre que algum evento altere a situação fática envolvendo a pessoa em questão.

Ora, o procedimento que altera ou extingue o conteúdo de um registro é denominado averbação. São averbados, portanto, atos que modificam conteúdo do registro como, por exemplo, o reconhecimento de filiação, a alteração de nome, o cancelamento do registro em caso de adoção - aqui, especificamente, com a consequente lavratura de um novo - etc ${ }^{29}$.

De acordo com o Código Civil brasileiro vigente, far-se-á averbação em registro público, dentre outras situações, de atos judiciais que declarem ou reconhecerem a filiação, senão vejamos:

Art. 10. Far-se-á averbação em registro público:

I - das sentenças que decretarem a nulidade ou anulação do casamento, o divórcio, a separação judicial e o restabelecimento da sociedade conjugal;

II - dos atos judiciais ou extrajudiciais que declararem ou reconhecerem a filiação. Grifeij ${ }^{30}$.

\footnotetext{
$\overline{{ }^{28}}$ BRASIL. Lei 6.015, de 31 de dezembro de 1973. Disponível em: http://www.planalto.gov.br/ccivil_03/leis/ L6015original.htm. Acesso em 14/05/2017.

${ }^{29}$ SOLLERO, Barbara Tuyama. Atos gratuitos do registro civil de pessoas naturais.ConteúdoJurídico, Brasília-DF: 03 dez. 2014. Disponível em: http://www.conteudojuridico.com.br/?artigos\&ver $=2.51112 \& s e o=1$. Acesso em: 10/09/2017.

${ }^{30}$ BRASIL. Lei 10.406, de 10 de janeiro 2002. Presidência da República. Disponível em: http://www.planalto.gov. br/ccivil_03/leis/2002/L10406.htm. Acesso em 12/03/2017.
} 
A averbação, por sua vez, está regrada no artigo 97 da Lei de Registros Públicos (lei $\mathrm{n}^{\circ}$ 6.015/73), o qual aduz que a "averbação será feita pelo oficial do cartório em que constar o assento à vista da carta de sentença, de mandado ou de petição acompanhada de certidão ou documento legal e autêntico, com audiência do Ministério Público"31.

Acerca do disposto no artigo 10 do Código Civil/02, há que se mencionar que o rol por ele apresentado é considerado meramente exemplificativo. Isso ocorre porque todo evento que implique a alteração ou cancelamento do respectivo registro deve ser averbado à sua margem, conforme já acima delineado. Além disso, ainda que se trate de título judicial, o registrador procederá a qualificação registraria, ou seja, dentre outros, verificará a autenticidade do título e se há menção ao trânsito em julgado da decisão, devendo recusar-se a proceder a averbação de sentença que não preencha os requisitos formais dispostos na lei ${ }^{32}$.

Posto isso, note-se que da mesma maneira ocorrerá com a sentença que declarar a multiparentalidade, a qual será averbada à margem do registro de nascimento, nos termos do artigo 97 da lei ${ }^{\circ}$ 6.015/73.Com isso, o oficial do Registro Civil das Pessoas Naturais titular da serventia em que se encontrar o registro a ser modificado lançará à margem do termo de nascimento os dados que a decisão judicial apresentar.

Evidencia-se na prática, com base na decisão proferida pela Exma. Sra. Dra. Juíza de Direito, Carine Labres, acima já apresentada, ocorrida em 07 de agosto de 2013, nos autos do processo judicial n $125 / 1.12 .0001221-8$, tramitado na Vara Judicial da Comarca de São Francisco de Assis-RS, a declaração da multiparentalidade com alguns efeitos imediatos a serem averbados nos assentos de nascimento dos beneficiados. Conforme mencionado no item anterior, trata-se de dois irmãos, menores de idade à época da decisão, os quais foram beneficiados com a maternidade socioafetiva, diante do falecimento da mãe biológica e reconstituição do vínculo conjugal pelo genitor. Requereram, contudo, a manutenção do vínculo biológico materno já declarado em seus registros. Veja-se o dispositivo:

Em face do exposto, JULGO PROCEDENTE o pedido formulado

\footnotetext{
31 BRASIL. Lei 6.015, de 31 de dezembro de 1973. Disponível em: http://www.planalto.gov.br/ccivil_03/leis/ L6015original.htm. Acesso em 14 mai 2017.

${ }^{32}$ LOUREIRO, Luiz Guilherme. Registros públicos: teoria e prática. 5. ed. rev., atual e ampl. Rio de Janeiro: Forense; São Paulo: Método, 2014, p. 159.
} 
na AÇÃO DECLARATÓRIA No 125/112.00001221-8, para o fim de declarar a maternidade socioafetiva de DAIANA BRONDANI GUIZOLFI ESPIG em relação a JARI ANTÔNIO LARA CORRÊA GUIZOLFI ESPIG JÚNIOR e a CARLOS EUGÊNIO LARA CORRÊA GUIZOLFI ESPIG NETO, devendo constar dos assentos de nascimento, sem prejuízo e concomitantemente com a maternidade biológica, o nome de Daiana Brondani Guizolfi Espig, com fulcro no art. 269, inc. I do CPC. Os menores passarão a se chamar JARI ANTÔNIO LARA CORRÊA BRONDANI GUIZOLFI ESPIG JÚNIOR E CARLOS EUGÊNIO LARA CORRÊA BRONDANI GUIZOLFI ESPIG NETTO, conforme vontade dos infantes (fl. 50), devendo constar dos assentos de nascimento, sem prejuízo e concomitantemente com o nome dos avós maternos, o nome dos avós socioafetivos, quais sejam: MAURY BRONDANI e LODOVINA CHEROBINI BRONDANI. COM o trânsito em julgado, expeça-se o respectivo mandado ao Registro Civil para que conste do assento de nascimento, sem prejuízo e concomitantemente com a maternidade biológica e o nome dos avós maternos, o nome da mãe socioafetiva e dos avós socioafetivos, nos termos supra ${ }^{33}$.

Posto isso, depois de realizadas as devidas averbações é expedida uma certidão atualizada com os dados ora acrescidos como, por exemplo, constando no nome dos beneficiados agora o sobrenome decorrente da maternidade socioafetiva, o nome da mãe socioafetiva, bem como dos avós maternos decorrentes desse vínculo ora solidificado.

Importante mencionar que os provimentos $\mathrm{n}^{\circ} 02$ (BRASIL, 2009a) e 03 (BRASIL, 2009b), oriundos do Conselho Nacional de Justiça - CNJ, com o intuito de uniformizar e aperfeiçoar as atividades dos serviços de registro civil das pessoas naturais, instituíram modelos únicos de certidão de nascimento, de casamento e de óbito a serem adotados pelos Ofícios de Registro Civil das Pessoas Naturais em todo o país.

Com base nos modelos pré-estabelecidos, verifica-se que o legislador optou por fazer constar os campos "filiação" e "avós" no documento, contudo, sem delimitar quantas ou quais pessoas integrariam aqueles campos, de modo a recepcionar a

\footnotetext{
33 RIO GRANDE DO SUL. AÇÃO DECLARATÓRIA No 125/112.00001221-8. Juíza Substituta - Dr. Carine Labres. Julgada em: 07/08/2013. Disponível em: www.tjrs.jus.br/inovajus/sentencas/12511200012218.odt Acesso em $18 / 08 / 2017$.
} 
multiparentalidade pelas serventias dos Registros Civis das Pessoas Naturais.

Ainda, diferentemente de como ocorre na adoção, onde a sentença judicial determina o cancelamento do registro original e a abertura de novo registro de nascimento, não se fazendo constar na certidão a origem da primeira filiação, na multiparentalidade, acredita-se, não há a necessidade de se realizar o procedimento de cancelamento, pois, ao invés de se destituir a filiação do indivíduo para dar-lhe outra diferente daquela, estar-se-á apenas cumulando dois tipos de filiação, quais sejam o biológico e socioafetivo, sendo necessária apenas a averbação nos termos lançados pela decisão judicial.

\section{CONCLUSÃO}

A partir da análise do estudo, percebe-se que a multiparentalidade decorre de vínculos que a pessoa adquire convivendo no seio de entidades familiares contemporâneas. É por meio das famílias reconstituídas, fundadas, acima de tudo, em laços afetivos, que os vínculos de parentalidade vêm sendo flexibilizados.

Por vezes, o indivíduo convive grande parte de sua vida amparado por figura paterna ou materna diferente daquela com que possui os vínculos biológicos, como é nos casos em que possui padrasto e/ou madrasta. Além disso, considera-os como pais e mães "de coração", diante do vínculo afetivo que com eles possui, além de ser visto por eles como filho e, ambos, reputados na sociedade como pai/mãe e filho(a).

A liberdade de constituição familiar coloca em cheque, para o direito de família, a necessidade de proporcionar amparo legal a todas as relações familiares ocorridas na sociedade. $\mathrm{O}$ afeto, despontando como fato gerador de arranjos familiares e, consequentemente, de vínculos de parentalidade, propõe ao ordenamento jurídico a necessidade de revisão de conceitos pré-existentes na legislação.

A Constituição Federal brasileira de 1988 inovou ao consagrar valores morais contemporâneos com vista a tutela da dignidade da pessoa humana. A partir disso, ocorreu a constitucionalização do direito de família, haja vista que o Código Civil que vigorava a época era datado de 1916 e totalmente despreparado para solucionar os conflitos familiares da época. Ainda assim, no ano de 2002, com a promulgação do novo Código Civil, continuou a se verificar que a entidade familiar contemporânea 
continuava a frente dos dispositivos legais desse novo Código.

Nesse sentido é o que ocorre com a multiparentalidade, a qual ainda não encontra amparo legal na legislação brasileira. Mais do que isso, sequer a filiação socioafetiva é regulamentada pelo Código Civil. Em razão disso é que todas as decisões favoráveis nesse sentido são construídas por entendimentos doutrinários, jurisprudenciais e, raramente, contam com o auxílio de dispositivos legais aleatórios.

A multiparentalidade é uma realidade fática atualmente. Em síntese, consiste na possibilidade de reconhecimento da filiação socioafetiva, mesmo quando já se possui o vínculo biológico declarado em registro de nascimento ou vice-versa. Atente-se que, aqui, ocorrerá a cumulação dos vínculos de filiação, fazendo-se com que a pessoa tenha declarado o duplo vínculo parental, com todos os consequentes reflexos havidos como se vínculo singular fosse.

Ademais, é por meio de princípios constitucionais e entendimentos jurisprudenciais que juízes, desembargadores e ministros do Supremo Tribunal Federal vêm embasando suas decisões. Princípios como o da dignidade da pessoa humana, da paternidade responsável, da solidariedade, da preservação do melhor interesse da criança e do adolescente passaram a ter força de lei quando o assunto é direito de família. Além do mais, há forte corrente no sentido de considerar a afetividade como princípio constitucional implícito na Carta Maior.

Registra-se que a afetividade, no caso da multiparentalidade, exerce a mesma função daquela compreendida na parentalidade socioafetiva. Aliás, somente com a verificação da parentalidade socioafetiva - embora carente de legislação, já consolidada no ordenamento jurídico brasileiro - e da biológica é que se poderá pleitear o reconhecimento do duplo vínculo de filiação.

Em uma sociedade permeada por relações frágeis, líquidas, individualizadas e carentes de solidariedade, valorizar o afeto, o amor, a felicidade e o bem-estar humano, é conduta a ser disseminada, ainda mais quando voltados à proteção e, até mesmo, estreitamento de laços familiares.

\section{REFERÊNCIAS}

ASSOCIAÇÃO DOS NOTÁRIOS E REGISTRADORES DO BRASIL. Qual a função do Cartório de Registro Civil? Disponível em: https://blog.cartorio24horas.com.br/quala-funcao-do-registro-civil-das-pessoas-naturais. Acesso em: 12 set. 2017. 
AZEVEDO, Álvaro Villaça. Código Civil comentado. São Paulo: Atlas 2003. BALBINO FILHO, Nicolau. Registro Civil das Pessoas Naturais. São Paulo: Atlas, 1983.

BRASIL. Conselho da Justiça Federal (STJ). Enunciados das Jornadas de Direito Civil. Disponível em: http://www.cjf.jus.br/enunciados/enunciado/588. Acesso em 07 out. 2017.

BRASIL. Constituição da República Federativa do Brasil de 1988, de 05 de outubro de 1988. Presidência da República. Disponível em:http://www.planalto.gov.br/ ccivil_03/constituicao/constituicaocompilado.htm. Acesso em 03 out. 2017.

BRASIL. PROJETO DE LEI N. ${ }^{\circ}$ 206-A, de 2007 (Do Sr. Clodovil Hernandes). Disponível em: http://www.camara.gov.br/proposicoesWeb/prop_ mostrarintegra;jsessionid $=$ E17678284877C036253C4E95E734FB59. node2? codteo $\mathrm{r}=513608 \&$ filename $=$ Avulso +-PL+206/2007. Acesso em: 12 out. 2017.

BRASIL. Lei 10.406, de 10 de janeiro 2002. Presidência da República. Disponível em: http://www.planalto.gov.br/ccivil_03/leis/2002/L10406.htm. Acesso em 12 mar. 2017.

BRASIL. Lei 11.340, de 7 de agosto de 2006. Presidência da República. Disponível em: http://www.planalto.gov.br/ccivil03/_ato2004-2006/2006/lei/111340.htm. Acesso em 07 out. 2016.

BRASIL. Lei 11.924, de 17 de abril de 2009. Presidência da República. Disponível em: http://www.planalto.gov.br/ccivil_03/_ato2007-2010/2009/lei/111924.htm. Acesso em 16 jun. 2017.

BRASIL. Lei 12.010, de 03 de agosto de 2009. Presidência da República. Disponível em: http://www.planalto.gov.br/ccivil_03/_ato2007-2010/2009/lei/12010.htm. Acesso em 07 dez. 2017.

BRASIL. Lei 6.015, de 31 de dezembro de 1973. Disponível em: http://www.planalto. gov.br/ccivil_03/leis/L6015original.htm. Acesso em: 14 maio 2017.

BRASIL. PL 6583/2013. Dispõe sobre o Estatuto da Família e dá outras providências. Disponível em: http://www.camara.gov.br/proposicoesWeb/ fichadetramitacao?idProposicao=597005. Acesso em: 03 out. 2017. 
BUNAZAR, Maurício. Pelas portas de Villela: um ensaio sobre a pluriparentalidade como realidade sóciojurídica. Revista IOB de Direito de Família, Porto Alegre, n. 59, p. 63-73, abr./maio 2010.

CALDERÓN, Ricardo. Reflexos da decisão do STF de acolher socioafetividade e multiparentalidade.Disponívelemhttp://www.conjur.com.br/2016-set-25/processofamiliar-reflexos-decisao-stf-acolher-socioafetividade-multiparentalidade\#_ftn2. Acesso em 07 out. 2017.

CALDERÓN, Ricardo. Reflexos da decisão do STF de acolher socioafetividade e multiparentalidade. Disponível em: http://www.conjur.com.br/2016-set-25/ processo-familiar-reflexos-decisao-stf-acolher-socioafetividade-multiparentalidade. Acesso em: 14 jun. 2017.

DIAS, Maria Berenice. Manual de direito das famílias. 10. ed. rev., atual. e ampl. São Paulo: Revista dos Tribunais, 2015.

DINIZ, Maria Helena. Curso de Direito Civil Brasileiro: Teoria Geral do Direito Civil. Saraiva; 2009.

FACHIN, Luiz Edson; PIANOVSKY, Carlos Eduardo. A Dignidade da Pessoa Humana no Direito Contemporâneo: uma contribuição à crítica da raiz dogmática do neopositivismo constitucionalista. ÂNIMA - Revista eletrônica do Curso de Direito Opet, $\mathrm{n}^{0}$ 5, Ano 2009.

GAGLIANO, Pablo Stolze; PAMPLONA FILHO. Novo curso de direito civil. São Paulo: Saraiva, 2009, p. 45.

GAMA, Guilherme Calmon Nogueira da. Das relações de parentesco. ln: DIAS, Maria Berenice; PEREIRA, Rodrigo da Cunha (coord.). Direito de família e o novo Código Civil. 3. ed. Belo Horizonte: Dei Rey, 2003.

GONÇALVES, Carlos Roberto. Direito civil brasileiro. direito de família. 13. Ed. São Paulo: Saraiva, 2016. v. 6.

GROENINGA, Giselle Câmara. Direito Civil. Direito de Família. HIRONAKA, Giselda M. F Novaes; BARBOSA, Aguida Arruda; VIEIRA, Cláudia Stein (coord.). São Paulo: RT, 2008. v. 7.

IRTDPJ BRASIL. Conheça um pouco da importância do registro público na vida 
do cidadão. Disponível em: http://www.irtdpjbrasil.com.br/NEWSITE/Registro\%20 Publico\%20x\%20Cidadania.pdf Acesso em: 12/12/2017.

LOUREIRO, Luiz Guilherme. Registros públicos: teoria e prática. 5. ed. rev., atual e ampl. Rio de Janeiro: Forense; São Paulo: Método, 2014.

PEREIRA, Rodrigo da Cunha. Concubinato e União Estável. 8. ed. rev. e atual. São Paulo: Saraiva, 2012.

PERROT, Michelle. O nó e o ninho. Veja 25 anos, São Paulo, Abril, 1993.

PÓVOAS, Mauricio Cavallazzi. A dignidade da pessoa humana, o afeto e as relações parentais: a multiparentalidade e seus efeitos. 2012. 11f. Dissertação (Mestre em Ciência Jurídica) - Programa de Mestrado em Ciência Jurídica da Universidade do Vale do Itajaí - UNIVALI, Santa Catarina. Disponível em: http://siaibib01.univali.br/ pdf/Mauricio\%20Cavallazzi\%20Povoas.pdf. Acesso em: 10 out. 2017.

RIO GRANDE DO SUL. Tribunal de Justiça do RS. Apelação Cível N 70062692876. Oitava Câmara Cível. Relator Des. José Pedro de Oliveira Eckert; Julgado em: 12/02/2015. Disponível em: https://tj-rs.jusbrasil.com.br/jurisprudencia/211663570/ apelacao-civel-ac-70064909864-rs/inteiro-teor-211663580?ref=juris-tabs. Acesso em: 10 out. 2017.

RIO GRANDE DO SUL. AÇÃO DECLARATÓRIA No 125/112.00001221-8. Juíza Substituta - Dr. Carine Labres. Julgada em: 07/08/2013. Disponível em: www.tjrs.jus. br/inovajus/sentencas/12511200012218.odt Acesso em 18 ago2017.

RIOS, Eduardo Higino. Fatos, atos e negócios jurídicos. Disponível em: $<$ https:// eduhrios.jusbrasil.com.br/artigos/322765094/fatos-atos-e-negocios-juridicos > . Acesso em: 12/09/2017

ROCHA, Marco Túlio de Carvalho. O conceito de família e suas implicações jurídicas: teoria sociojurídica do direito de família. Rio de Janeiro: Elsevier, 2009.

ROSA, Conrado Paulino da. Ifamily: um novo conceito de família? São Paulo: Saraiva, 2013.

SÃO PAULO. TJSP. Relator(a): Alcides Leopoldo e Silva Júnior; Comarca: Itu; Órgão Julgador: 1 Câmara de Direito Privado; Data do julgamento: 14/08/2012; Data de registro: 14/08/2012. Disponível em: www.tjsp.jus.br. Acesso em: 10 set. 2017. 
SILVA, Giana de Marco da; CATALAN, Marcos Jorge. O Registro de Biparentalidade Homoafetiva: um Estudo de Caso. Revista Síntese Direito de Família, v. 16, n. 92, p. 22, out/nov. 2015.

SOLLERO, Barbara Tuyama. Atos gratuitos do registro civil de pessoas naturais. Conteúdo Jurídico, Brasília-DF: 03 dez. 2014. Disponível em: http://www. conteudojuridico.com.br/?artigos\&ver $=2.51112 \&$ seo $=1$. Acesso em: 10 set. 2017 .

SOUTO MAIOR, Heraldo Pessoa. Durkheim e a família: Da "Introdução à Sociologia da Família” à "Família Conjugal". Revista ANTHROPOLÓGICAS, ano 9, v. 16, n. 1, p. 7-30, 2005. Disponível em: https://periodicos.ufpe.br/revistas/revistaanthropologicas/ article/viewFile/23622/19277. Acesso em: 13 out. 2017.

TARTUCE, Flávio. Manual de direito civil: volume único. 6. ed. rev., atual. e ampl. Rio de Janeiro: Forense; São Paulo: Método, 2016.

TEIXEIRA,Ana Carolina Brochado; RODRIGUES, Renata de Lima. Amultiparentalidade como nova estrutura de parentesco na contemporaneidade. Revista Brasileira de Direito Civil, v. 4, p. 21-22, abr./jun. 2015.

VECCHIATTI, Paulo Roberto Iotti. Manual da Homoafetividade: possibilidade jurídica do casamento civil, da união estável e da adoção por casais homoafetivos. Rio de Janeiro: Forense; São Paulo: Método, 2008.

VILLELA, João Batista. Família Hoje. Entrevista a Leonardo de Andrade Mattietto. In: BARRETO, Vicente (org.). A nova família: problemas e perspectivas. Rio de Janeiro: Renovar, 1997.

WELTER, Pedro Belmiro. Teoria Tridimensional no Direito de Família: reconhecimento de todos os direitos das filiações genética e socioafetiva. Disponível em: http://www.mprs.mp.br/imprensa/noticias/id17076.htm?impressao=1. Acesso em: 12 ago. 2017. 